\title{
Schatzki's Ring: \\ Two Cases with Mid-Esophageal Location
}

\author{
Hamid A. Durrani, MD., FACG., Ashaq H. Naqashbandi, M. Ch., Akhtar Purvez, M.S. \\ Kashmir, India
}

DOI: http://dx.doi.org/10.5915/21-2-13316

\begin{abstract}
The Schatzki's ring is a narrow annular stricture that radiographically appears as a circumferential membrane or web projecting into the lumen at right angle to the long axis of the lower part of the esophagus. This report presents two cases of Schatzki's ring situated almost mid-esophagus, far proximal from the usual location at the squamo-columnar junction. Such rings in a mid-esophageal location have not previously been reported in the literature.
\end{abstract}

Key words: Schatzki's ring, esophageal webs, bouginage.

\section{Introduction}

A distal esophageal web was originally described by Templeton. ${ }^{1}$ Schatzki and Gray ${ }^{2}$ and Ingelfinger and $\mathrm{Kramer}^{3}$ were the first to attribute symptoms to this lesion. Later Schatzki and Gray described their further experiences with this disease entity. Many patients may be asymptomatic ${ }^{5}$ but dysphagia almost invariably occurs when the ring diameter is $13 \mathrm{~mm}$ or less. These rings involve only the mucosa and submucosa and not the esophageal smooth muscle. Microscopically, squamous epithelium covers the upper surface of ring and the columnar epithelium covers the lower surface. ${ }^{6}$ In all of the cases reported so far, the ring is situated at the esophagogastric junction above a sliding hiatal hernia.

\section{Case Histories:}

Two Kashmiri patients, a 47 year old male and a 51 year old female, presented with intermittent dysphagia of 3 and 5 years duration, respectively. A general physical examination revealed no significant findings. A barium esophagogram demonstrated

From the Departments of Medicine /Gaestroenterology Division), Surgery, and Otolaryngology, Government Medical College, Srinagar, Kashmir (India).

Reprint requests: Dr. A Purvez, 7-Chowk Saida Kadal, Srinagar-190 003, Kashmir, India.

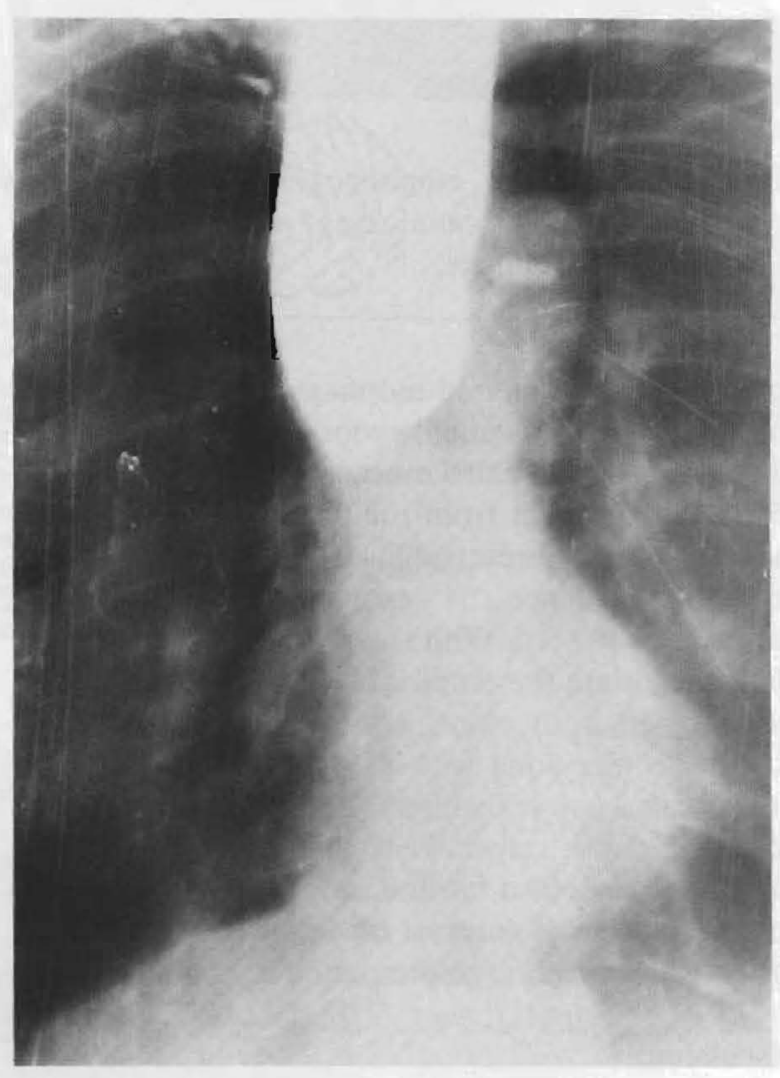

Figure 1. Barium esophagogram showing constriction in mid-esophagus. 
some cases ${ }^{9}$ and no question of resection of the involved segment, as was in vogue in older times.

\section{References.}

1. Templeton FE: A description of roentgenolic anatomy, physiology of the esophagus, stomach, and doudenum. Chicago: University of Chicago Press, 1944.

2. Shatzki R Gray JE: Dysphagia due to diaphragm like localized narrowing in lower esophagus (lower esophageal ring) Am J Roentgenol 1953; 70: 911-922.

3. Ingelfinger JF, Kramer P: Dysphagia produced by contractile ring in lower esophagus. Gastroenterology 1953; 23: 419-421.

4. Schatzki R, Gray JE: The lower esophageal ring. Am J Roentgenol 1956; 75: 246-268.

5. Orringer MD: Diverticula and miscellaneous con- ditions of esophagus. In: Sabiston, MD, Jr. (ed), Textbook of Surgery. Philadelphia: WB Saunders Company/Agaku-Shoin/Saunders, 1986; pp 728-729.

6. Postlethwait RW: Surgery of the Esophagus. Connecticut: Appleton-Century-Crofts, 1979; pp 259-266.

7. Conn JH: Exophageal webs. In: Hardy, JD. (ed), Textbook of Surgery. Philadelphia, Toronto: J.B. Lippincott Company, 1970; pp 767-770.

8. Eckardt V, Dagradi AE, Slempien SJ: The esophagogastric (Schatzki) ring and reflux esophagitis. Am J Gastroenterol 1972; 58:525-529.

9. Mossberg SM: Lower esophageal ring treated by pneumatic dilatation. Gastroenterology 1965; 48: 118-121. 